\title{
Study on the retention behaviour of low-molar-mass polystyrenes and polyesters in reversed-phase liquid chromatography by evaluation of thermodynamic parameters
}

\author{
Citation for published version (APA): \\ Philipsen, H. J. A., Claessens, H. A., Lind, H., Klumperman, B., \& German, A. L. (1997). Study on the retention \\ behaviour of low-molar-mass polystyrenes and polyesters in reversed-phase liquid chromatography by \\ evaluation of thermodynamic parameters. Journal of Chromatography, A, 790(1-2), 101-116. \\ https://doi.org/10.1016/S0021-9673(97)00739-5
}

DOI:

10.1016/S0021-9673(97)00739-5

Document status and date:

Published: 01/01/1997

\section{Document Version:}

Publisher's PDF, also known as Version of Record (includes final page, issue and volume numbers)

\section{Please check the document version of this publication:}

- A submitted manuscript is the version of the article upon submission and before peer-review. There can be important differences between the submitted version and the official published version of record. People interested in the research are advised to contact the author for the final version of the publication, or visit the DOI to the publisher's website.

- The final author version and the galley proof are versions of the publication after peer review.

- The final published version features the final layout of the paper including the volume, issue and page numbers.

Link to publication

\footnotetext{
General rights

- You may freely distribute the URL identifying the publication in the public portal. follow below link for the End User Agreement:

www.tue.nl/taverne

\section{Take down policy}

If you believe that this document breaches copyright please contact us at:

openaccess@tue.nl

providing details and we will investigate your claim.
}

Copyright and moral rights for the publications made accessible in the public portal are retained by the authors and/or other copyright owners and it is a condition of accessing publications that users recognise and abide by the legal requirements associated with these rights.

- Users may download and print one copy of any publication from the public portal for the purpose of private study or research.

- You may not further distribute the material or use it for any profit-making activity or commercial gain

If the publication is distributed under the terms of Article $25 \mathrm{fa}$ of the Dutch Copyright Act, indicated by the "Taverne" license above, please 


\title{
Study on the retention behaviour of low-molar-mass polystyrenes and polyesters in reversed-phase liquid chromatography by evaluation of thermodynamic parameters
}

\author{
H.J.A. Philipsen ${ }^{\mathrm{a}, *}$, H.A. Claessens ${ }^{\mathrm{b}}$, H. Lind ${ }^{\mathrm{a}}$, B. Klumperman ${ }^{\mathrm{c}}$, A.L. German ${ }^{\mathrm{c}}$ \\ ${ }^{a}$ Océ Technologies, Research and Development Department, P.O. Box 101, 5900 MA Venlo, Netherlands \\ ${ }^{\mathrm{b}}$ Laboratory of Instrumental Analysis, Eindhoven University of Technology, P.O. Box 513, 5600 MB Eindhoven, Netherlands \\ ${ }^{\mathrm{c}}$ Laboratory of Polymer Chemistry, Eindhoven University of Technology, P.O. Box 513, 5600 MB Eindhoven, Netherlands
}

Received 9 April 1997; received in revised form 26 June 1997; accepted 30 June 1997

\begin{abstract}
Polymers can be characterized under sorption conditions, to obtain information on molar mass and chemical composition. In order to get a better understanding of their retention behaviour under such conditions, the evaluation of thermodynamic parameters obtained from van't Hoff analyses on low-molar-mass polystyrenes (PS) and polyesters (PE) in various THF-water mixtures on a $\mathrm{C}_{18}$ column is described in this study. Linear van't Hoff behaviour was observed in almost all cases. Negative values for both $\Delta H$ and $\Delta S$ were found for both PS and PE oligomers, which increase with increasing \%THF. For $\Delta S$ this is explained from multi-site attachment effects. For PS, the non-linear relations between $\Delta H$ and $\Delta S$, and degree of polymerization $(p)$ could be properly described by the Stockmayer-Fixman equation. Although less clear, similar trends were found for PE. For PS, evidence for penetration effects of oligomer chains into the bonded chains was obtained. Martin plots for both PS and PE were shown to be non-linear in all investigated eluent compositions. The extent of non-linearity is suggested to depend on the conformation of a polymer in solution. No distinct enthalpy-entropycompensation temperature (EECT) independent of $p$ was found for PS, thus confirming the findings of an earlier study in which no exact molar mass independence was found under critical conditions. Further evaluation of EECT for PS oligomers revealed a retention mechanism independent of the binary eluent composition. This indicates that conclusions from this study can also be used for a qualitative understanding of sorption mechanisms in the gradient elution mode. Finally, for PS it was shown that $\Delta G$ equals zero under critical conditions, thus confirming theoretical predictions. (C) 1997 Elsevier Science B.V.
\end{abstract}

Keywords: Retention behaviour; Thermodynamic parameters; Polystyrenes; Polyesters; Polymers

\section{Introduction}

The characterization of synthetic polymers by liquid chromatographic methods differing from sizeexclusion chromatography (SEC), has gained considerable attention during the past decade. Induced by

\footnotetext{
*Corresponding author.
}

the increasing complexity of (co)polymers, gradient elution [1-4] as well as isocratic [5-7] liquid chromatographic methods have been applied to characterize these products according to chemical composition. Recently we have demonstrated the applicability of gradient polymer elution chromatography (GPEC) for the characterization of low-molarmass polyesters [8-10]. By GPEC under reversed- 
phase conditions (RP-GPEC), evidence of differences in inter- and intra-molecular microstructure in copolyesters was obtained. In a further study on the influence of solubility effects in RP-GPEC, it was shown that although precipitation/re-dissolution effects were present, retention of amorphous polyesters throughout the whole investigated molar mass range (approximately 0-30 000) was largely determined by sorption effects [11]. The same was found by Snyder et al. [12,13] as well as by ourselves [14] for polystyrenes.

A method that has frequently been used to study the (sorption governed) retention mechanism of lowmolar-mass solutes in reversed-phase liquid chromatography (RPLC) is to investigate the temperature dependence of isocratic retention [15-27]. From the experimentally determined van't Hoff plots (ln $k$ versus $1 / T, k=$ retention factor), thermodynamic parameters can be deduced which can be used to gain information on the influence of both the stationary and the mobile phase and of the solute itself on the retention mechanism.

In order to get a better understanding of their retention behaviour, in this study the determination and evaluation of thermodynamic parameters for low-molar-mass polystyrenes and polyesters is described. Hereto, retention factors for a large number of oligomers of styrene and of a copolyester that has also been used in our other studies [8,11], were determined as a function of temperature and composition of the binary THF-water eluent combination on a $\mathrm{C}_{18}$ column. Polystyrenes were chosen for reasons of their structural simplicity as compared to polyesters, which makes it easier to study the influence of chain length more independent of differences in functionality and chemical composition of the polymer backbone. Although homologous series and oligomers have been taken into account in a few comparable studies by other authors $[16,19,27]$, the nature of the polymers studied here, is significantly different. It will be shown here that different chromatographic behaviour is observed as compared to, for instance polyethyleneoxides, especially with respect to molar mass influences. Despite the fact that measurements had to be carried out under isocratic conditions, conclusions can also be used for a qualitative understanding of the retention mechanisms in the gradient elution mode which is mostly applied for non-exclusion polymer chromatography. This is especially valid for the higher-molar-mass products for which it is known that chromatographic elution occurs within a very small range of eluent compositions $(\Delta \varphi)$ [28], which is the same range in which under isocratic conditions, measurable retention factors can be obtained.

\section{Theoretical}

The retention factor, $k$, in chromatography is defined as:

$k=\left(t_{\mathrm{r}}-t_{0}\right) / t_{0}=K_{\mathrm{d}} \phi$

in which $K_{\mathrm{d}}$ is the chromatographic equilibrium constant, $t_{\mathrm{r}}$ is the retention time, $t_{0}$ is the retention time of an unretained component and $\phi$ is the phase ratio [volume stationary phase $\left(V_{\mathrm{s}}\right)$ /volume mobile phase $\left.\left(V_{\mathrm{m}}\right)\right]$. This equation can be re-written into Eq. (2), expressing the temperature dependence of retention in chromatography, in which $\Delta G^{0}, \Delta H^{0}$ and $\Delta S^{0}$ are the Gibbs free energy, standard enthalpy and standard entropy of transfer of a solute from the mobile to the stationary phase.

$$
\begin{aligned}
\ln k & =-\Delta G^{0} / R T+\ln \phi \\
& =-\Delta H^{0} / R T+\Delta S^{0} / R+\ln \phi
\end{aligned}
$$

If $\Delta H^{0}$ and $\Delta S^{0}$ are invariant over the studied temperature range, these quantities can be directly determined from a plot of $\ln k$ versus $1 / T$, the van't Hoff plot, for $\Delta S^{0}$ provided that $\phi$ is known. For non-linear plots, these parameters can be approximated from the partial derivative of $\ln k$ to $1 / T$ of a polynomial function [21].

For an accurate determination of $\Delta S^{0}, \phi$ must be known. This is not straightforward, since the value $V_{\mathrm{s}}$, being the effective part of the stationary phase that actually participates in the sorption process is difficult to obtain. It strongly depends on the exact structure of the derivatized silica material e.g. bonding type, bonding density, pore width etc., which can be highly different between various column materials [29]. The approximation adopted in this study was proposed by Sentell and Dorsey [30] and has also been used in other thermodynamic studies $[20,21,25]$. It determines the actual volume of the 
alkyl chains taking part in the sorption process, and is given by:

$V_{\mathrm{s}}=(\% C)(M)\left(W_{\mathrm{p}}\right) /(100)(12.011)\left(n_{\mathrm{c}}\right)(\rho)$

where $\% C$ is the carbon load as determined from elemental analysis, $M$ is the molar mass of the bonded alkyl ligand $(\mathrm{g} / \mathrm{mol}), W_{\mathrm{p}}$ is the mass of the bonded packing in the column $(\mathrm{g}), 12.011$ is the molar mass of carbon, $n_{\mathrm{c}}$ is the number of carbons in the alkyl ligand and $\rho$ is the density $\left(\mathrm{g} / \mathrm{cm}^{3}\right)$ of the bonded alkyl ligand.

For higher-molar-mass products that are taken into account in this study, steric exclusion can affect the accessible pore volume for a specific solute, thus influencing the column hold up volume $\left(V_{\mathrm{o}}\right)$ (and $t_{\mathrm{o}}$ ) and $V_{\mathrm{s}}$. It has been shown that $k$ for high-molar-mass solutes can be determined from [12]:

$k_{\mathrm{M}}=\left(t_{\mathrm{r}, \mathrm{M}}-t_{\mathrm{sec}, \mathrm{M}}\right) /\left(t_{\mathrm{sec}, \mathrm{M}}\right)$

in which $t_{\mathrm{sec}, \mathrm{M}}$ is the retention time of the solute with molar mass $M$, under non-sorbing conditions. The effect on $V_{\mathrm{s}}$ is difficult to account for. It must be kept in mind, that this parameter only influences $\phi$ and therefore will cause a small shift of all $\Delta S^{0}$ values in the same direction, which, however, may be slightly different for solutes that significantly differ in hydrodynamic volume. This will be further discussed in the results section.

In earlier studies, van't Hoff analysis has been used to study the effect of the stationary phase on the retention process. Non-linear van't Hoff behaviour was observed under certain conditions which could be explained from a phase transition of the $\mathrm{C}_{18}$ column material [20]. This influences the partition process, which has been shown to be the main process determining retention on $\mathrm{C}_{18}$ derivatized silica [31]. Partitioning and partial insertion of the alkyl chain was found to be dependent on the carbon number of a homologous series, which could be concluded from a discontinuity in the plot of $\Delta H^{0}$ vs. the carbon number [19]. The shape of the van't Hoff plot was shown to vary with the nature and composition of the mobile phase type which is caused by differences in the entropically driven, hydrophobic effect due to differing extents of $\mathrm{H}$ bridge formation in various solvent types [21]. The existence of different conformations of (low-molar- mass) oligomers during the chromatographic process could also be proved from varying shapes of van't Hoff plots [16]. Furthermore, it was shown that these plots may be used for the determination of physical and thermodynamic constants that are difficult to obtain by other methods [23].

The change in Gibbs free energy for an oligomeric series with degree of polymerization, $p$, and two, possibly different end groups: $\mathrm{X}-\mathrm{Y}_{\mathrm{p}}-\mathrm{Z}$ can be expressed as [32]:

$\Delta G^{0}=\Delta G_{\mathrm{x}}^{0}+\Delta G_{\mathrm{z}}^{0}+p \Delta G_{\mathrm{y}}^{0}$

Since $\ln (k)$ usually increases linearly with $p$, which is known as the Martin equation, the dependence between $\ln (k)$ and Gibbs free energy can be written as [32]:

$$
\ln (k)=\left[\left(-\Delta G_{\mathrm{x}}^{0}-\Delta G_{\mathrm{z}}^{0}\right) / R T+\ln (\phi)\right]-p\left(\Delta G_{\mathrm{y}}^{0} / R T\right)
$$

A linear increase in $\ln (k)$ with $p$ has been found for various oligomer types in reversed-phase as well as normal-phase systems [6,33,34], although most studies were restricted to $p<20$.

To check whether retention mechanisms for various situations are comparable, Melander et al. have applied the concept of compensation temperature based on enthalpy-entropy compensation [15]. This temperature, $\beta$, can be determined from the slope of a plot of $\ln (k)$ vs. $\Delta H^{0}$ according to Eq. (7):

$\ln \left(k_{\mathrm{T}}\right)=-\Delta H^{0}(1 / T-1 / \beta) / R-\Delta G_{\beta} / R \beta+\ln (\phi)$

If the same physical-chemical process determining the energies of the retention process is operative for the various situations taken into account in the compensation plot, then a linear dependence, and therefore only one compensation temperature, will be found. It was also shown that for statistical reasons, $k$ can at best be taken at the average value of the tested temperature range [15]. The concept of enthalpyentropy compensation has been used in several studies in order to investigate agreements in and differences between retention mechanisms [1719,25]. Further theoretical backgrounds concerning the meaning and application of the concept were described in Ref. [35]. 


\section{Experimental}

\subsection{Polymer sample and narrow disperse fractions}

The polystyrenes used for the experiments were narrow standard polystyrenes from Waters (Milford, MA, USA). $M_{\mathrm{p}}$ values (molar mass at the maximum of the molar mass distribution) as supplied by the manufacturer are: 418, 2900, 3600, 5400, 8500 and 35000 . In all cases, butyllithium was used as the initiator. Polydispersity of all standards was $<1.10$. Standard 2900 in which oligomers 1-30 could be separately distinguished was used for van't Hoff analysis. The molar mass of each respective oligomer equals: $M=58+104 p$.

The polyester sample used was a copolyester resin consisting of adipic acid (A), isophtalic acid (I) and dipropoxylated bisphenol-A (D) (sample PE1 from $[8,10])$. The molar ratio A:I:D is approximately $0.12: 0.38: 0.50$ (NMR), the acid number is $20 \mathrm{mg}$ $\mathrm{KOH} / \mathrm{g}$ and the polystyrene equivalent molar masses as determined by SEC are $3500\left(M_{\mathrm{n}}\right)$ and $7900\left(M_{\mathrm{w}}\right)$ respectively. For more detailed information on the composition and characterization of the polyester sample, the reader is referred to [8]. Low polydispersity fractions of the polyester were isolated by SEC. Detailed information on the preparation and characterization of these fractions has been described in [10]. Polydispersity of most of the standards was $<1.10$. The identity of the main components in each fraction was determined by a comparison of the RP-GPEC chromatograms of the unfractionated polyester which had already been extensively characterized [8], and the respective fraction.

Oligomers and their respective molar masses, that were used in the van't Hoff analysis are indicated in the RP-GPEC chromatogram in Fig. 1. PS oligomers up to $p=30$ and for PE oligomers up to $p=13$ were taken into account.

\subsection{HPLC equipment}

The column used was a NovaPak $\mathrm{C}_{18}$ column (Waters, $d_{\mathrm{p}}=4 \mu \mathrm{m}$, pore size $60 \AA, 75 \times 3.9 \mathrm{~mm}$ ). The solvents used for HPLC were water, LiChrosolv quality from Merck (Darmstadt, Germany) and tetrahydrofuran (THF), HPLC grade from Rathburn (Brunschwig Chemie, Amsterdam, Netherlands). To

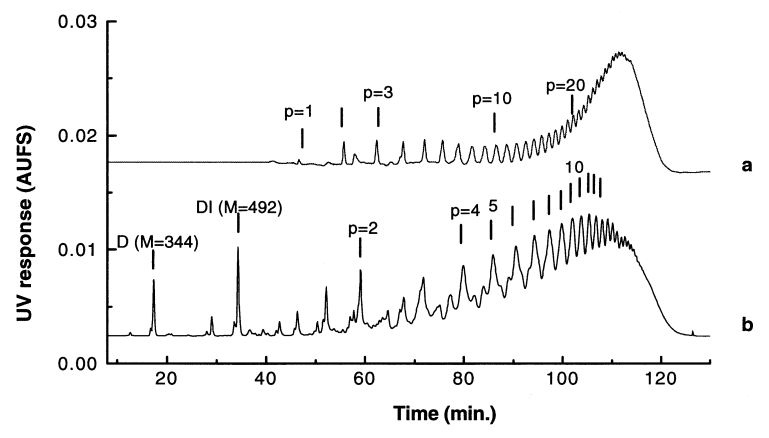

Fig. 1. RP-GPEC chromatogram of PS (a) and PE (b). Oligomer peaks taken into account for van't Hoff analysis: PS: all oligomers up to $p=30$, PE: all indicated oligomers. Identity of PE oliogomers: D: dipropolylated bisphenol-A, $\mathrm{D}_{\mathrm{p}} \mathrm{Ac}_{\mathrm{p}}$ (Ac: acid), molar mass: $(469 p+18)$. Chromatographic conditions: column, NovaPak $\mathrm{C}_{18}(75 \times 3.9 \mathrm{~mm})$, temperature: $35^{\circ} \mathrm{C}$, eluent: $\mathrm{THF}-$ water (both with $200 \mu \mathrm{l}$ of acetic acid per litre added) $(20: 80, \mathrm{v} / \mathrm{v})$ to $(90: 10)$ in $140 \mathrm{~min}$, flow: $1.0 \mathrm{ml} / \mathrm{min}$, detection: $\mathrm{UV}$ at $263 \mathrm{~nm}$ (PS) and $277 \mathrm{~nm}(\mathrm{PE})$.

both solvents, $200 \mu \mathrm{l}$ of acetic acid, analyticalreagent quality from Merck, per litre was added. For HPLC, the solvents were constantly sparged with helium $(20 \mathrm{ml} / \mathrm{min})$. All solvent mixtures were made by volumetric mixing by the HPLC pump, no premixes were used. All HPLC experiments were performed, using a Waters 600E 4 solvent gradient pump, and a 717 autosampler from Waters. The detector was a variable wavelength detector, Jasco (Tokyo, Japan) type 975, which was set at $254 \mathrm{~nm}$. The column temperature was controlled using a thermostat type Mistral from Spark-Holland (Emmen, Netherlands). Chromatograms were recorded using the Baseline-815 system from Waters. The column was connected by a $0.02 \mathrm{~cm}$ I.D. tubing of about $50 \mathrm{~cm}$ to the injector, which was led through the column thermostat to ensure temperature equilibration before entering the column.

\subsection{Determination of phase ratio and ksec values}

For the determination of the phase ratio, $\phi$, of the used column, Eq. (3) was used to calculate $V_{\mathrm{s}}$. \%-C was determined in duplicate by elemental analysis using an Heraeus CHN-O Rapid apparatus and was found to be $7.3 \%$. $W_{\mathrm{p}}$ of two $7.5 \mathrm{~cm}$ columns was determined after thoroughly drying of the complete 
packing that had been quantitatively removed from the column and was found to be $0.793 \mathrm{~g} \pm 1 \%$ (maximum deviation between average and maximum of duplicate measurements: $\operatorname{dev}_{\max }$ ). The identity of the derivates reacted onto the silica matrix were determined by ${ }^{29} \mathrm{Si}$ nuclear magnetic resonance spectroscopy (NMR) using a Bruker MSL 400 spectrometer and were found to be octadecyldimethylsilyl and trimethylsilyl (endcap) respectively. The molar ratio of both derivates was determined by ${ }^{13} \mathrm{C}$ NMR and was found to be $1: 1$. Therefore, $\% \mathrm{C}$ due to octadecyldimethylsilyl was determined to be $6.35 \%$ and $\% \mathrm{C}$ resulting from the endcap was $0.95 \%$. Densities for the respective derivates have been determined by Cheng [34] and equal to 0.8607 for octadecyldimethylsilyl and 0.8638 for trimethylsilyl respectively. Therefore $V_{\mathrm{s}}$, being the sum of the respective contributions of both derivates could be calculated and was found to be $0.094 \mathrm{ml} \pm 2 \%\left(\mathrm{dev}_{\max }\right)$.

$V_{\mathrm{m}}$ was determined gravimetrically in duplicate from the differential weight of the column filled with dichloromethane and methanol respectively, a method that was also adopted by other workers [20], and was found to be $0.52 \mathrm{ml} \pm 1 \%\left(\operatorname{dev}_{\max }\right)$. Hence, $\phi$ was found to be $0.18 \pm 3 \%$.

To determine $t_{\mathrm{sec}}$ as a function of molar mass, which is necessary to calculate $k$ (Eq. (4)), retention times for the narrow standard polystyrenes mentioned in 3.1., were measured in duplicate at $40^{\circ} \mathrm{C}$, which is the average temperature used for the van't Hoff analysis, using a flow-rate of $2.0 \mathrm{ml} / \mathrm{min}$ in $100 \%$ THF. This eluent composition is known to be non-retentive for polystyrene [7]. Hereto, standards were dissolved in the eluent up to a concentration of $1 \mathrm{mg} / \mathrm{ml}$ from which $2 \mu \mathrm{l}$ was injected. Retention times were found to vary between $0.18 \mathrm{~min}$ for PS-35000 and $0.26 \mathrm{~min}$ for PS-418 respectively. From a third order polynomial fit of $\log$ (molar mass) versus retention time, $t_{\mathrm{sec}}$ for each individual molar mass could be determined. Retention times for low dispersity polyester standards were measured under the same conditions and were found to vary between $0.210 \mathrm{~min}$ for fraction 1 and $0.235 \mathrm{~min}$ for fraction 9. Retention time differences due to a change of the hydrodynamic volume with varying temperatures are known to be small [7] and were therefore neglected in this study.

\subsection{Experiment strategy}

For the thermodynamic evaluations, isocratic measurements were performed at various binary eluent compositions, i.e. 39, 44, 47, 55, 60, 64, 67 and 69\% THF in water respectively, at temperatures of 10,20 , $30,40,55$ and $70^{\circ} \mathrm{C}$, the range of which is known to be broad enough for an adequate van't Hoff analysis [22]. Hereto $10 \mu \mathrm{l}$ of solutions of $10 \mathrm{mg} / \mathrm{ml} \mathrm{PS-}$ 2900 in THF and $40 \mathrm{mg} / \mathrm{ml}$ of the unfractionated polyester in THF were injected in duplicate, using a flow-rate of $2.0 \mathrm{ml} / \mathrm{min}$. After $21 \mathrm{~min}$, eluent composition was rapidly changed to $100 \%$ THF to elute the remaining, high-molar-mass components. Therefore, $k$ values that could be measured approximately were in the range of $0-100$. After $2.5 \mathrm{~min}$, the system was rapidly returned to initial conditions and the system was re-equilibrated during $6.5 \mathrm{~min}$. This equilibration time was found to be sufficient to obtain constant retention times. Also the injected amounts were checked to be in the range in which no overloading and therefore no influence on retention time occurred. For the identification of the oligomer numbers in each chromatogram, PS-418 and two polyester standards lying in the molar mass range that was observed in the isocratic analysis under the conditions chosen, were also injected. When the identity of one or more peaks was known, the other ones could also be easily identified. System temperature was held constant until all samples were measured at all eluent compositions. For statistical reasons, isocratic eluent compositions at one temperature and temperatures itself were changed randomly. For the determination of $k$ values, average values of the duplicate measurement of retention times were taken.

\section{Results and discussion}

Van't Hoff plots were constructed for the oligomers indicated in Section 3.1 at each eluent composition. Examples are shown in Fig. 2. Especially the higher-molar-mass oligomers could not be measured isocratically at low \% THF and, in some cases, at low temperatures. This is due to the fact that the isocratic parameter $S$, which is defined as $-d(\ln$ $k) / d \varphi$ increases with molar mass causing the range 

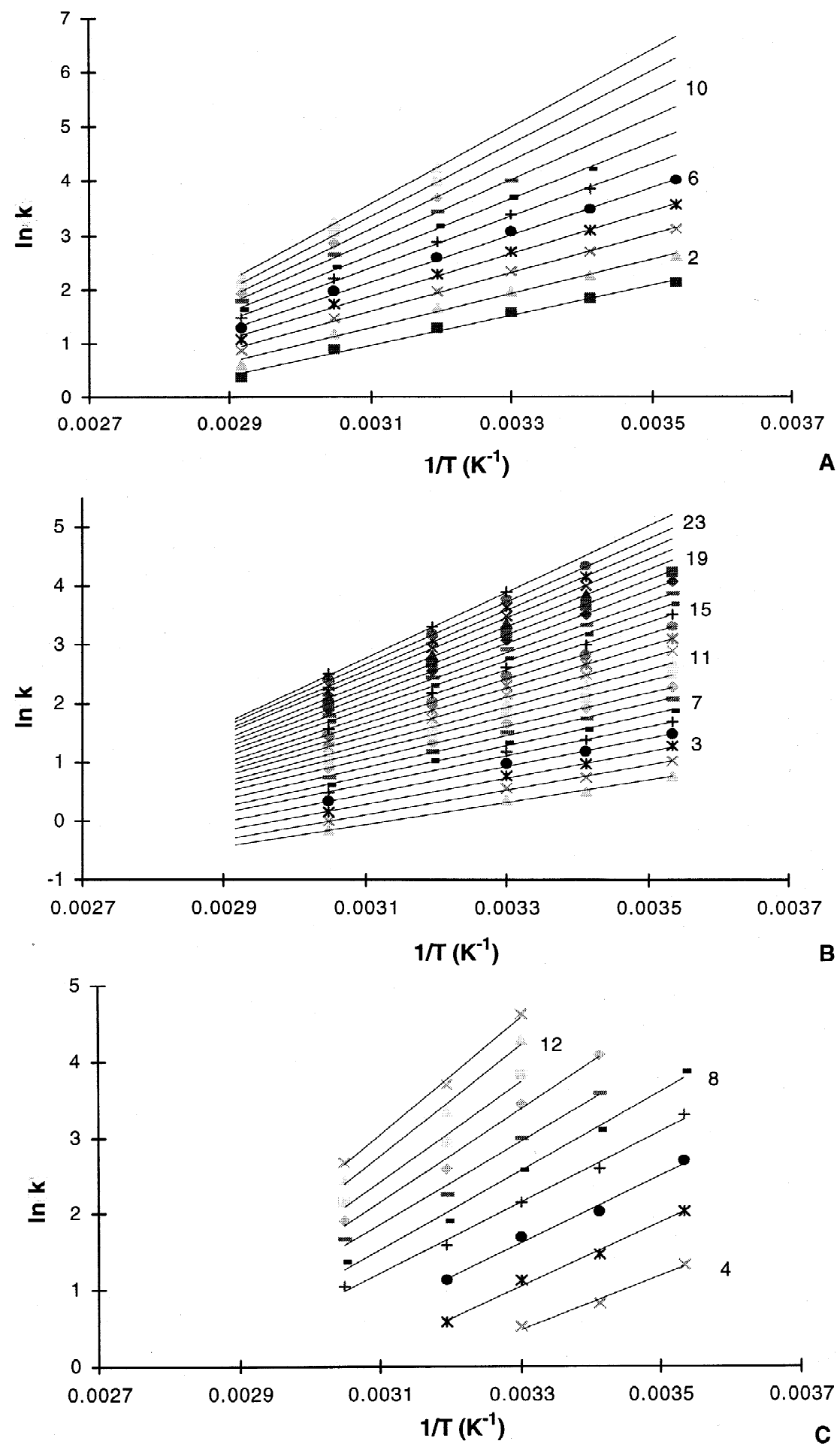

Fig. 2. Van't Hoff plots of PS oligomers at 55\% THF (A) and 67\% THF (B) and PE oligomers at $67 \%$ THF (C). Oligomer numbers indicated in figures. Chromatographic conditions: see Section 3. 
of eluent compositions in which $k$ lies between 0 and 100 , to decrease [36].

In all cases, linear plots are obtained. The coefficient of regression in most cases exceeds 0.99. Nevertheless, for low molar mass polystyrenes (PS) where 6 data points are available, it can be seen that plots tend to be slightly curved, indicating a small temperature dependence of $\Delta H$ and $\Delta S$ (see for instance Fig. 2A). An increase of both $\Delta H$ and $\Delta S$ towards less negative values, at lower temperatures has been observed more often for low-molar-mass solutes [21]. It has been ascribed to the hydrophobic effect causing an increased order in the mobile phase due to the decreasing affinity of the solute for the mobile phase at lower temperatures, thus giving rise to a more entropy-governed retention mechanism. An alternative explanation will be discussed later on in this report. For reasons of simplicity, in most cases the observed slight curvatures were neglected and approximated as straight lines. For polyester (PE) the scattering around the linear plot in most cases is somewhat higher as compared to polystyrene (PS). This is due to the fact that peaks belonging to
PE oligomers are less well defined as compared to PS. Since they are in fact composite peaks containing more than one component [8], they give rise to broader peaks, the retention time of which is less accurate to determine.

From the obtained van't Hoff plots, $\Delta H$ and $\Delta S$ were calculated. For $\Delta H$ in all cases negative values were found indicating that sorption for all oligomers is an exothermic process. $\Delta H$ values increase (become less negative) with increasing \% THF which can be explained from the increased affinity of the oligomers to the mobile phase. This is in accordance with the fact that water is a non-solvent for PS and PE, whereas THF is a thermodynamically good solvent.

The calculated $\Delta S$ values were negative in all cases, indicating increased ordering of the system. In most cases, $\Delta S$ increases (becomes less negative) with increasing \% THF, which can be observed from Fig. 3. At first sight this may seem strange, since at higher \% THF, less ordering of the oligomers in the mobile phase is expected due to the increasing thermodynamic quality of the solvent, which should
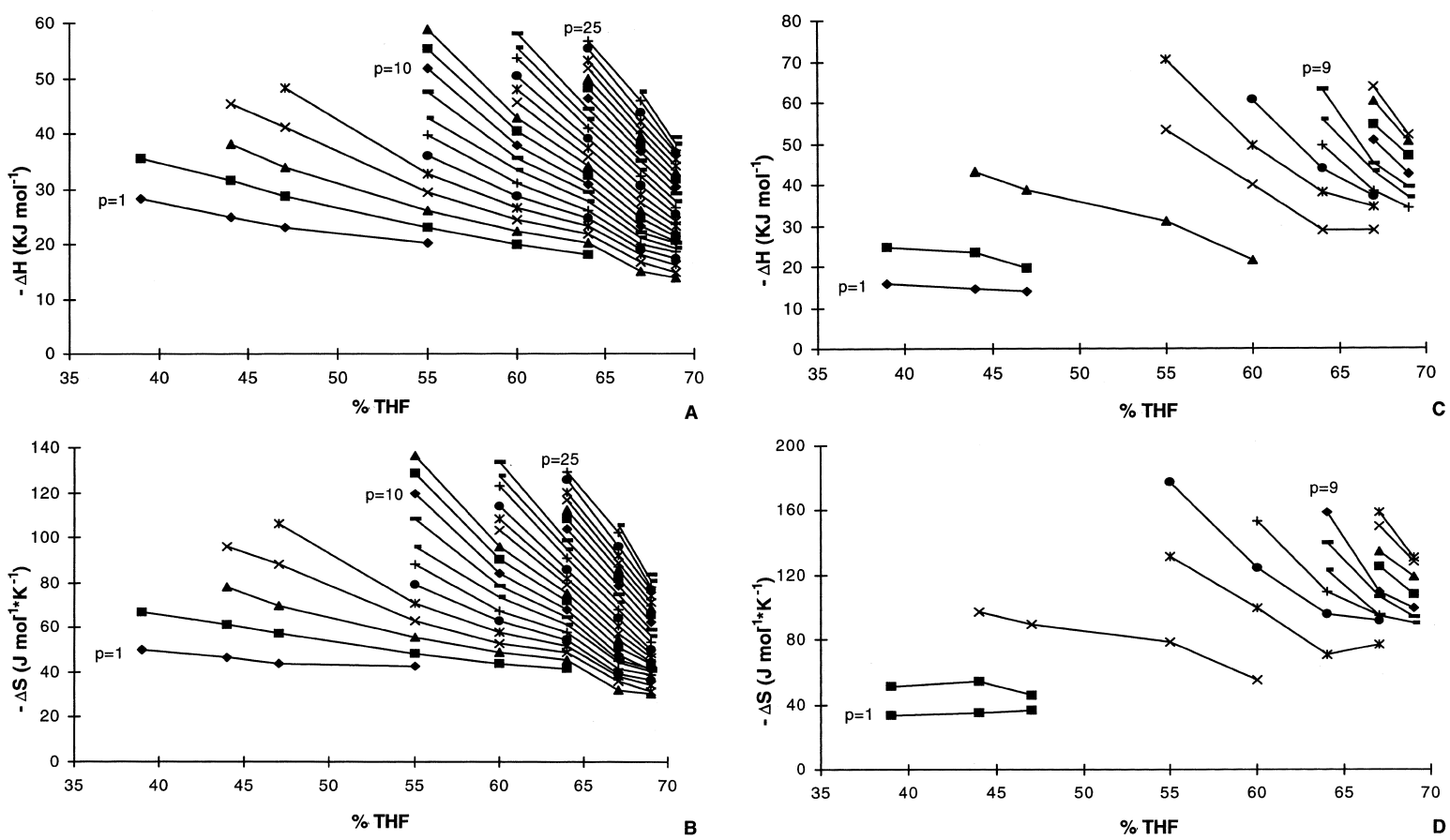

Fig. 3. $-\Delta H(\mathrm{~A}, \mathrm{C})$ and $-\Delta S(\mathrm{~B}, \mathrm{D})$ versus \% THF for various oligomers of PS (A, B) and PE (C, D). Oligomer numbers indicated in figures. Chromatographic conditions: see Section 3. 
give rise to a decrease in $\Delta S$. Decreasing $\Delta S$ values with increasing \%-organic modifier, especially for low molar mass solutes, were also found by other workers [25]. Obviously for the relatively high molar mass substances under study here, decreasing ordering in or at the stationary phase with increasing $\% \mathrm{THF}$ is more important. Interactions of large molecules with the stationary phase are probably mainly based on adsorption rather than partitioning [32]. Furthermore it is known that different sites of macromolecules can interact with a sorbent simultaneously, which is known as multi-site attachment [37]. This process gives rise to a sharp decrease in the degrees of freedom of the macromolecule when going from the mobile to the stationary phase. Due to increased affinity towards the mobile phase with increasing \% THF, the average number of oligomer sites that will simultaneously interact with the sorbent will decrease, giving rise to increased disorder. This effect obviously overrules the increasing disorder in the mobile phase, thus causing higher $\Delta S$ values.

The fact that for very low-molar-mass PS, at increasing \% THF increasing $\Delta S$ values are found also, cannot be explained from multi-site attachment. It is probable that, like for many low-molar-mass solutes, sorption will be dominated by partitioning [22]. At higher \% THF, the structure of the $\mathrm{C}_{18}$ layer will be more 'open' and oriented towards the mobile phase [29]. This means that penetration of this layer will be easier, thus causing less ordering of solutes that will be partitioned in this layer and a net increase in $\Delta S$.

For the first two oligomers of PE, (slightly) decreasing $\Delta S$ values with increasing \% THF are observed. Due to the more polar nature of these oligomers as compared to PS, ordering effects in the mobile phase due to mutual association, in order to reduce the surface area exposed to water, are more explicitly caused by the ability of hydrogen bonding. At higher \% THF, due to the increased affinity to the mobile phase, this effect will diminish, thus causing less ordering. For higher-molar-mass PE, such ordering effects can also occur, but, like for PS, at higher $\% \mathrm{THF}$, decreased ordering in the mobile phase is overruled by less ordering in the stationary phase, thus causing an increase in $\Delta S$.

For all oligomers, of both PS and PE, the mag- nitude of $\Delta H$ is always greater (more negative) than that of $T \Delta S$. This indicates that enthalpy plays a more pronounced role in the total retention process than does entropy. For PS, for the quotient $\Delta H / T \Delta S$, values between 1.4 and 1.6, dependent on $p$ and $\% \mathrm{THF}$, were calculated, whereas for PE oligomers these values in most cases were approximately 1.3. From the observed trends of $\Delta H / T \Delta S$ versus $p$, it could be concluded that these differences are highly significant. Obviously, retention for PS is somewhat more enthalpy driven, which may be caused by the higher affinity of the non-polar PS toward the nonpolar stationary phase. Furthermore, for PS a monotonously increasing contribution of $\Delta H$ was found with increasing \% THF, indicating a relatively increasing role of enthalpy. For instance, $\Delta H / T \Delta S$ for $p=15$ increased from 1.41 at $60 \%$ THF to 1.61 at $69 \%$ THF. For PE, the quotient changed in the opposite direction and changes were much smaller.

In Fig. $4, \Delta H$ and $\Delta S$ for PS oligomers are plotted as a function of $p$ for various eluent compositions. The decrease in both parameters with $p$, of course, is trivial. From a critical look at the enthalpy curves, it can be observed that $\Delta H$ seems to decrease slightly more than proportional with $p$. To check, whether this effect is real, at first the standard deviation of retention time was calculated from 10 determinations at $10^{\circ} \mathrm{C}$ and $70^{\circ} \mathrm{C}$ respectively for both high- and low-molar-mass oligomers, and was found to be $0.020 \mathrm{~min}$ for low-molar-mass oligomers and 0.035 min for high-molar-mass oligomers. Furthermore, from a comparison of the results from several polynomial fits of $\log (M)$ versus retention time, the inaccuracy in $t_{\mathrm{sec}}$ was estimated to be $2 \%$. Thus, inaccuracy for the retention factor of each individual oligomer could be calculated. By applying these results in the van't Hoff plots, the standard deviation in $\Delta H$ was found to be $4 \%$ for the lowest-molarmass oligomers and $1 \%$ for the highest oligomers. After applying errors bars in the $\Delta H$ curve at $64 \%$ THF no linear curve could be found which included all data points (results presented elsewhere [38]). Furthermore, from a linear regression analysis, non randomly scattered residual values were found, indicating a non-linear dependence between $p$ and $\Delta H$.

The more than proportional decrease of $\Delta H$ can possibly be understood from the fact that retention in reversed-phase chromatography is mainly determined 

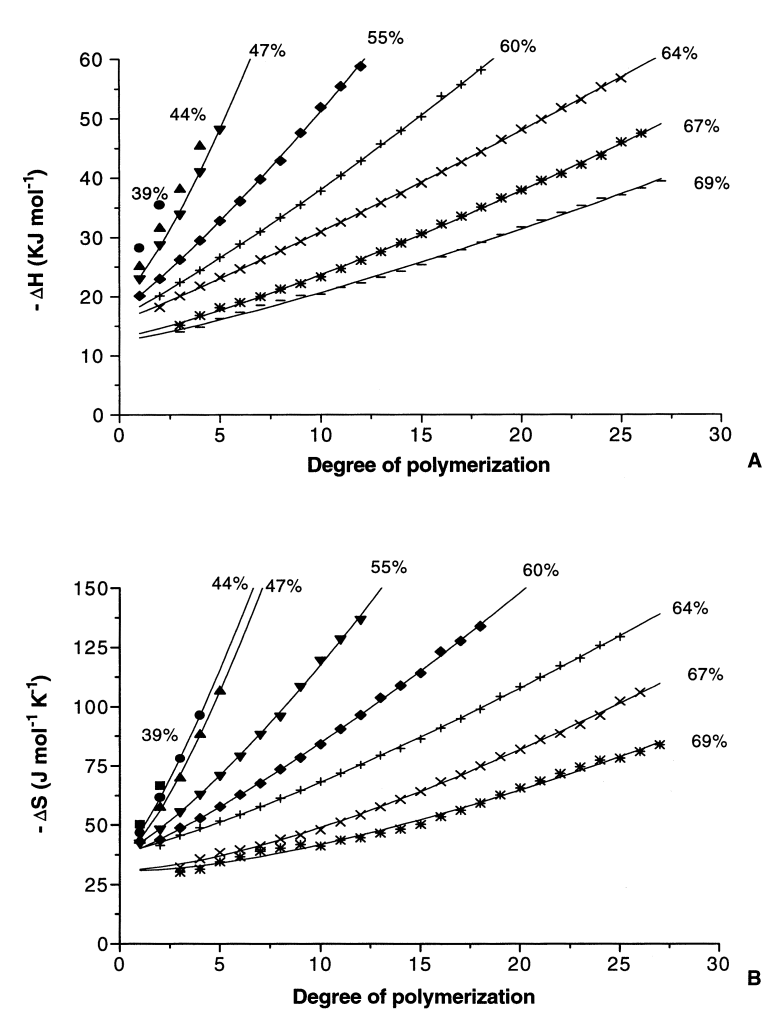

Fig. 4. $-\Delta H$ (A) and $-\Delta S$ (B) versus degree of polymerization of $\mathrm{PS}$ at various eluent compositions. \% THF indicated in figures. Chromatographic conditions: see Section 3.

by molar surface [16]. Molar surface can be considered as being proportional to the square of the hydrodynamic radius. Hydrodynamic volume scales with molar mass according to:

$H V \propto[\eta] M$

in which $H V$ is the hydrodynamic volume and $[\eta]$ is the intrinsic viscosity, which is related to molar mass according to the equation of Stockmayer and Fixman [39]:

$[\eta]=K_{\theta} M^{0.5}+K^{\prime} M$

After proper substitution, it can be found that molar surface of a polymer coil in solution scales with its molar mass as:

$A_{\mathrm{s}} \propto A M+B M^{4 / 3}$

where $A$ is proportional to $K_{\theta}$ and $B$ is proportional to $K^{\prime} ; A_{\mathrm{s}}$ represents molar surface. It is known that $K_{\theta}$ is a constant, independent of solvent, i.e. it relates the intrinsic viscosity of a polymer to its molar mass under theta conditions. On the other hand, $K^{\prime}$ depends on the solvent composition. The value of $K^{\prime}$ increases with increasing solvent quality. Based on this, it would be expected that the observed curvature in Fig. 4 would increase with increasing fraction THF in the binary solvent mixture. This is hard to observe by visual inspection of the curves and also from the numerical values of the parameters, since these values contain some uncertainty due to irregularities in some of the curves, the nature of which will be discussed later on. However, from Fig. $4 \mathrm{~A}$ it is clear that Eq. (10) properly describes the experimentally determined relations of enthalpy versus degree of polymerization. Coefficients of regression in all cases exceed 0.999 .

In the enthalpy curve at $67 \%$ THF but especially at $69 \%$ THF, an irregularity at a molar mass of about 1000 appears. A critical review of our data, revealed that this cannot be explained from errors in, for instance, $t_{\mathrm{sec}}$ [38]. As mentioned earlier, especially for the lowest-molar-mass oligomers where 6 data points for van't Hoff plots are available, a slight curvature is observed. Therefore, it was considered that in these cases the determination of $\Delta H$ is not based on the same number of data points as for higher oligomers. To see whether a different data treatment can cause the observed irregularity, the enthalpy curve at $69 \%$ THF was also constructed with $\Delta H$ values determined from van't Hoff plots in which for all oligomers only the highest three temperatures were taken into account. From the result, shown in Fig. 5, it can be seen that this reveals an even more distinct discontinuity. Therefore, the effect is believed to be real and not the result of artefacts in our measurements. A discontinuity in the plot of $\Delta H$ (and $\Delta S$ ) versus the carbon number of several homologous series has earlier been described by Tchapla et al. [19]. The phenomenon was explained from the fact that the lower members of the series, up to a number that was slightly less than the carbon number of the bonded chain of the stationary phase, can penetrate into the bonded layer. This involves a closer contact between the solute and the stationary phase ligand, giving rise to a different retention mechanism. It is remarkable 

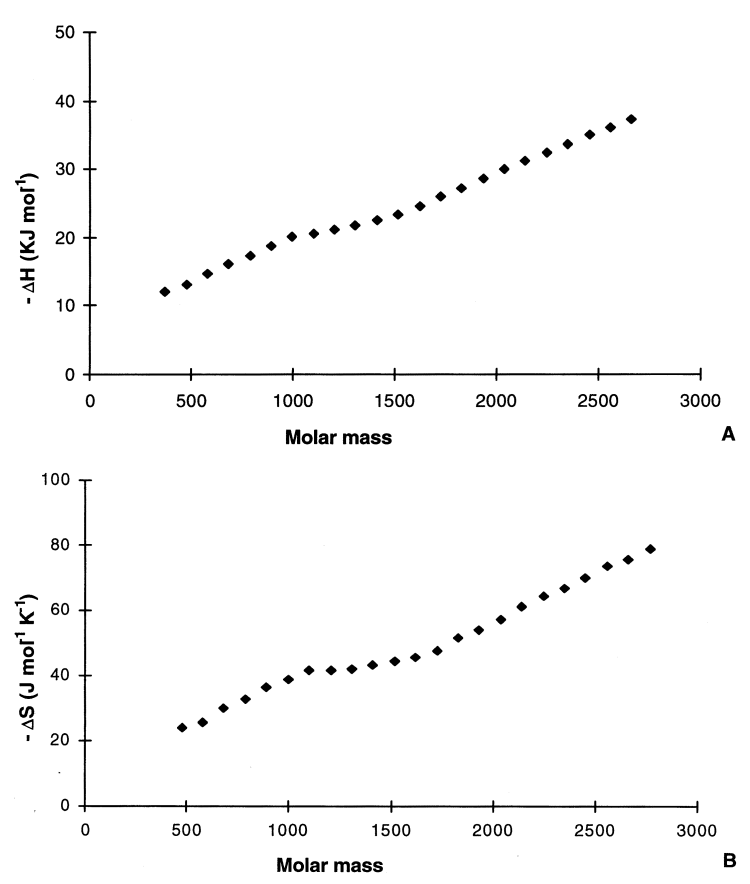

Fig. 5. $-\Delta H$ (A) and $-\Delta S$ (B) as function of molar mass of PS at $69 \%$ THF. Both $\Delta H$ and $\Delta S$ values calculated from van't Hoff plots based on measurements at 40,55 and $70^{\circ} \mathrm{C}$. Chromatographic conditions: see Section 3.

that the same kind of phenomenon seems to be observed for PS, since the hydrodynamic volume of PS oligomers, due to the bulky aromatic parts, is much larger as compared to members of the homologous series, which might be expected to hamper penetration in the bonded layer. The oligomer number at which the discontinuity occurs is approximately 13, which almost equals the critical carbon number $\left(n_{\mathrm{c}}\right)$ for several homologous series on a $\mathrm{C}_{18}$ bonded layer, which was found to be 14. It must be considered, however, that the length of the linear PS chain in such a case is $(26+4)$ since each repeating unit contains two carbon atoms and each oligomer chain contains one butyl end group. In terms of the mechanism suggested by Tchapla, a change in retention mechanism at such a relatively high chain length of the oligomers might be due to a folding of the linear oligomer chain causing insertion of both ends into the bonded layer, although this is speculative.

The fact that at lower \% THF no indications of penetration effects are observed from the enthalpy curves can likely be ascribed to a levelling effect of these large scale functions on the rather minor effect. In this respect, plots of selectivity versus $p$ are better suited, as will be pointed out later on. Nevertheless the results indicate partitioning effects of oligomers up to a molar mass higher than would have been expected at forehand.

Penetration effects may also provide an alternative explanation for the observed curvature in the van't Hoff plots of the low-molar-mass oligomers (Fig. 2). At lower temperatures, the $\mathrm{C}_{18}$ chains become more rigid which will especially affect the retention behaviour of solutes that (partly) penetrate into the layer, thus giving rise to curved van't Hoff plots. This effect was already reported for other low-molarmass solutes in various reversed-phase systems [40].

Similar to enthalpy, entropy decreases more than proportionally with $p$. This can be observed from Fig. 4B, where, for the curve at $64 \% \mathrm{THF}$, error bars, being the result of the same error analysis as for enthalpy, are shown. Furthermore, it can be seen that relations between $\Delta S$ and $p$ can also be described properly by this equation, with coefficients of regression in all cases exceeding 0.999 .

Like for the enthalpy curves, discontinuities are found at higher \% THF, which become more obvious when data for all oligomers are treated in the same way (Fig. 5), thus again accounting for partitioning effects.

In Fig. $6, \Delta H$ and $\Delta S$ of PE oligomers are plotted versus molar mass. Compared to PS, the curves are less smoothed and data points show more scatter. This is probably due to the fact that the nature of the various PE oligomers under study differ in the kind of end group resulting in different energies of interaction. This will cause the part between brackets of Eq. (6) to be different, thus giving rise to a less gradual increase of $\Delta H$ and $\Delta S$ with molar mass. Although less clear, similar trends are observed for $\mathrm{PE}$ as compared to PS.

Due to its large repeating unit, of course for PE no transitions in the $\Delta H$ and $\Delta S$ curves can be seen, since only the first two or three oligomers might be expected to penetrate into the bonded layer. Therefore, the number of data points available in the relevant range of molar masses is too low to visualise such effects.

In Fig. 7, plots of $\ln (k)$ versus $p$ for PS are shown. 

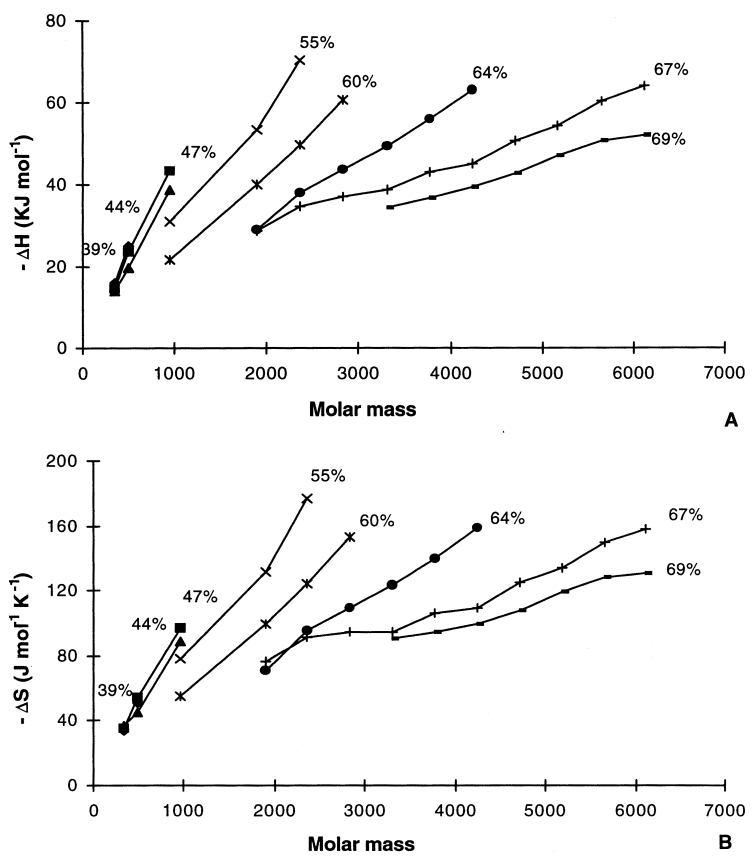

Fig. 6. $-\Delta H(\mathrm{~A})$ and $\Delta S$ (B) as function of molar mass of PE at various eluent compositions. \% THF indicated in figures. Chromatographic conditions: see Section 3.
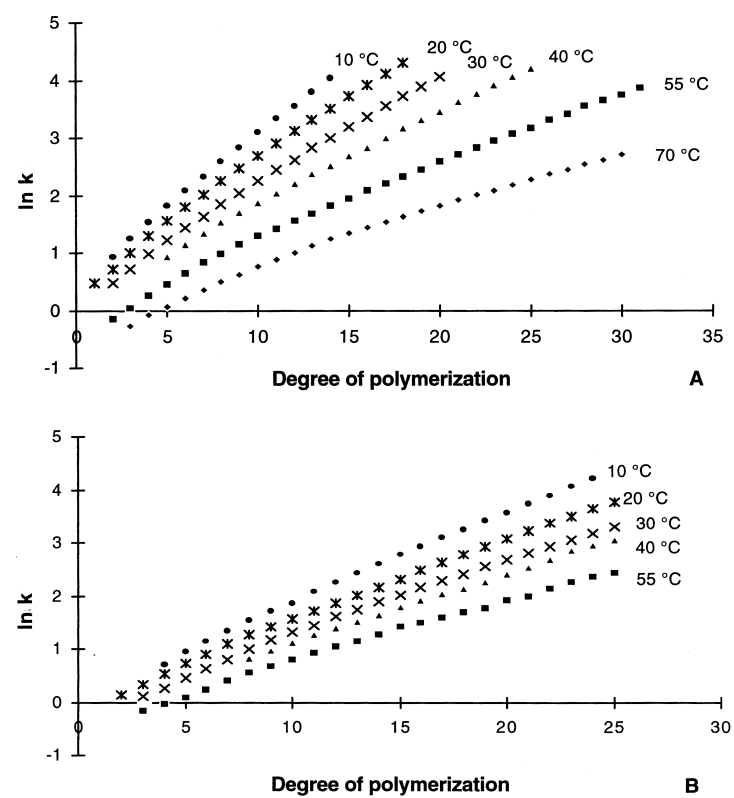

Fig. 7. $\ln k$ versus degree of polymerization of PS (Martin plots) at $64 \% \mathrm{THF}$ (A) and $69 \% \mathrm{THF}$ (B) at various temperatures. Temperatures indicated in figures. Chromatographic conditions: see Section 3.
It is obvious that these Martin plots are non linear in all cases. Curvature in the very low $p$ range has been observed earlier and can be ascribed to the effect of the (butyl) end group on the total free energy of transfer of the first oligomers [32]. Deviations from linearity in the higher $p$ range for other types of oligomers and homologues have been shown to occur at the critical carbon number and have been ascribed to a change in sorption mechanism from 'dissolution' in the bonded layer to physical adsorption [19,41]. Indeed, in some of the curves in Fig. 7, a distinct discontinuity seems to be present. This of course coincides with the value of $p$, for which also discontinuities in the enthalpy and entropy curves were found, which could have been expected when looking at Eq. (6).

A more detailed look upon the respective retention effects can be obtained from plots of selectivity, $\alpha\left(k_{\mathrm{p}+1} / k_{\mathrm{p}}\right)$ versus $p$. In Fig. 8, where such plots are shown for $64 \%$ THF and 69\% THF, it can be seen that two regions can be distinguished. The relatively steep decrease of $\alpha$ up to $p=14$, as compared to
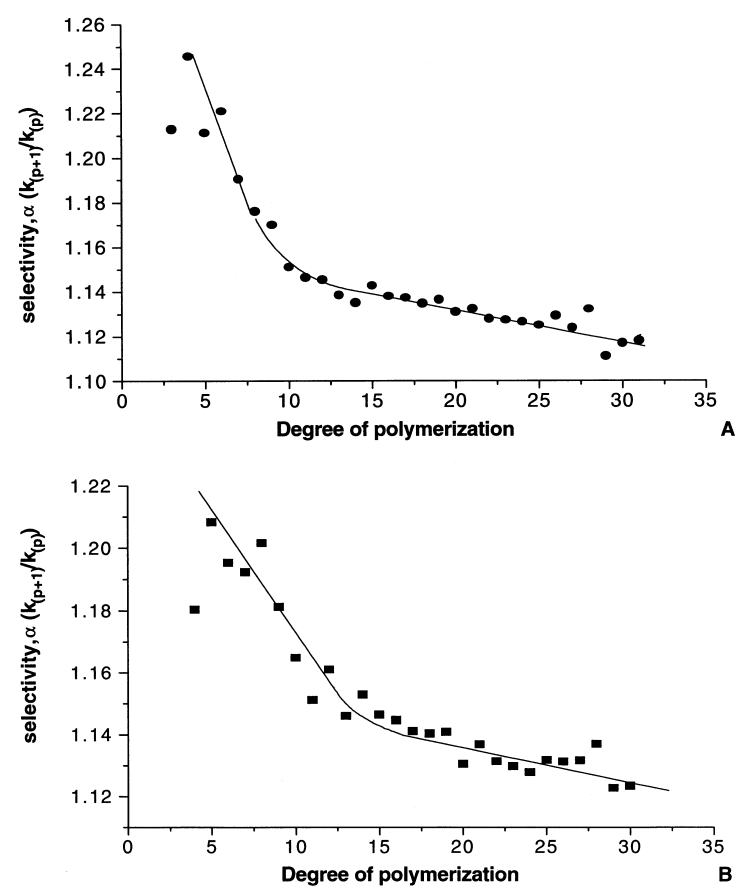

Fig. 8. Selectivity, $\alpha,\left(k_{(n+1)}^{\prime} / k_{(n)}^{\prime}\right)$ versus degree of polymerization of PS at $64 \% \mathrm{THF}$ and $55^{\circ} \mathrm{C}(\mathrm{A})$ and at $69 \% \mathrm{THF}$ and $30^{\circ} \mathrm{C}(\mathrm{B})$. Chromatographic conditions: see Section 3. 
higher values of $p$, again indicates a different retention mechanism, thus further accounting for partitioning effects. The distinctly decreasing values of $\alpha$ at $p>14$ clearly evidence the non-linearity of the Martin plots at higher degrees of polymerization. Monotonously decreasing values of $\alpha$ seem logical since selectivity will reach a value of one at infinite molar mass.

A critical look at the data of other workers (Fig. 1 of Ref. [33] and Fig. 7a of Ref. [12]) reveals that slight curvature for PS at higher $p$ seems to be found as well, in spite of the fact that linearity is claimed. Finally from Fig. 9 it can be concluded that non linearity also occurs for PE, the cause of which can certainly not be ascribed to penetration effects, due to the relatively high molar masses.

From the thermodynamic data presented above, it can be concluded that the curvature can be ascribed to entropic effects. The non linear decrease of $\Delta H$ which would cause retention to increase more than proportionally with $p$, obviously is overcompensated by the non linear decrease of $\Delta S$, affecting retention in the opposite direction. These effects found for both PS and PE which significantly differ in chemical nature, suggest that curved Martin plots are a universal phenomenon for non-polar and moderately polar polymers in the investigated separation system. Our measurements confirm earlier observations by Larman et al., [12] who predicted a bending off of the straight line plot, based on a calculation of isocratic retention data from gradient elution runs.

Concurrently, very recently it was reported for polyethyleneglycol/polyethyleneoxide (PEG) that in

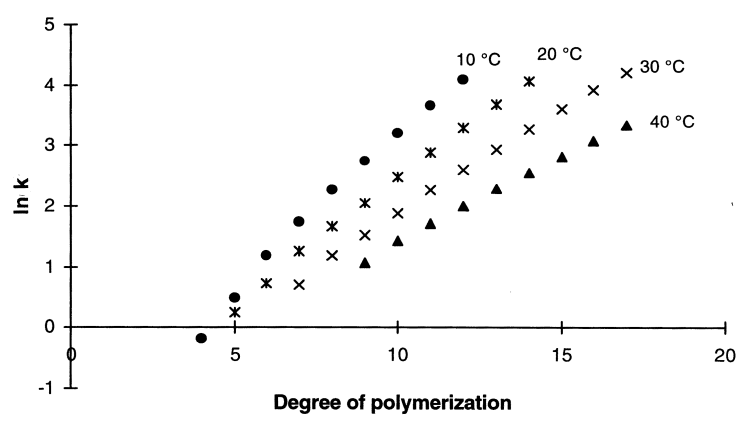

Fig. 9. $\ln k$ versus degree of polymerization of PE (Martin plots) at $69 \% \mathrm{THF}$ at various temperatures. Temperatures indicated in figures. Chromatographic conditions: see Section 3. an acetonitrile-water system both $\Delta H$ and $\Delta S$, and therefore also $\ln (k)$, increase linearly with $p$, up to a molar mass of at least 100000 [27]. The difference as compared to our results can possibly be explained from a different polymer conformation and the different nature of the organic modifier.

The concept of enthalpy-entropy-compensation for oligomers with varying degree of polymerization was tested at $40^{\circ} \mathrm{C}$ which is the average value of the tested temperature range. Results are shown in Fig. 10 where plots of $\ln (k)$ versus $\Delta H$ (Eq. (7)) for the respective oligomers at various eluent compositions are given. For both PS and PE, like in the Martin plots, distinct curvature is found. This indicates a monotonously decreasing enthalpy-entropy-compensation-temperature (EECT) for higher oligomers which again demonstrates a change in retention mechanism with molar mass. For higher oligomers, retention increases less than proportionally with $\Delta H$, which is due to the increasing dominance of entropy effects caused by multi-site adsorption. For PS at higher \%THF, again two different, almost linear
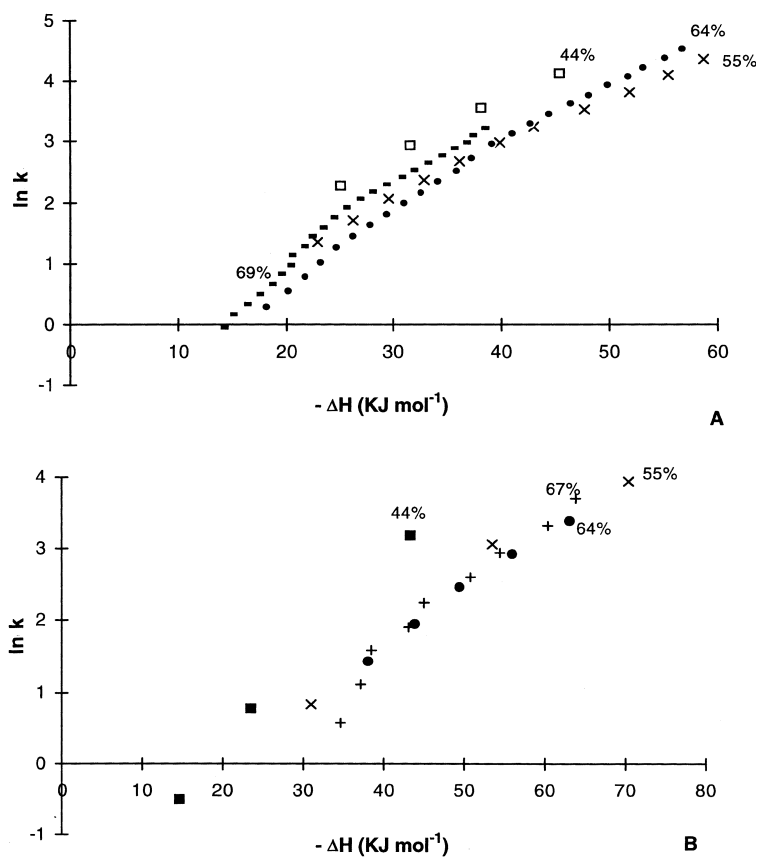

Fig. 10. $\ln k$ versus $\Delta H$ (enthalpy-entropy compensation plot) for PS (A) and PE (B) oligomers with varying molar mass at various eluent compositions. \% THF indicated in figure. Temperature: $40^{\circ} \mathrm{C}$. Other chromatographic conditions: see Section 3. 
parts can be observed. For these two parts, at $69 \%$ THF two different EECT's could be determined, e.g. $307 \pm 24^{\circ} \mathrm{C}$ (95\% confidence intervals) for oligomers $3-15$ and $147 \pm 6^{\circ} \mathrm{C}$ for oligomers $16-26$. The fact that both values differ significantly, again indicate a difference in retention mechanism for the lower oligomers compared to the higher analogons, which has already been ascribed to insertion into the bonded layer.

The physical meaning of an EECT for oligomers with varying $p$ is the temperature at which retention becomes independent of molar mass [27]. The conditions at which this occurs in liquid chromatography are known as critical conditions $[5,7,42]$. The fact that no distinct EECT can be found for the investigated polymers would suggest that no conditions can be established at which retention times of polymers with varying molar mass exactly match. This is in agreement with results from our recent study in which it was reported that, although conditions could be established at which retention was nearly independent of molar mass, in none of the investigated cases exact molar mass independence was found [7]. Results reported here probably provide an explanation for this observation.

Enthalpy-entropy-compensation was also verified for various oligomers in varying eluent compositions. For all individual PS oligomers, linear dependence with a high degree of correlation was obtained ( $r^{2}>0.99$ in all cases), indicating that the retention mechanism is constant in the tested range of \% THF. The finding of an EECT in reversed-phase chromatography has more often been observed for both polar and non-polar solutes [43].

Various effects, e.g. dominance of enthalpy effects, penetration into the bonded layer and the more than linear increase in enthalpy and entropy with $p$, have been shown to occur throughout the whole investigated range of eluent compositions. This, together with the observation that the retention mechanism of PS with \% THF is invariant, indicates that conclusions from this study can also be used for a qualitative understanding of the sorption mechanisms in the gradient elution mode. This is especially valid for the higher-molar-mass oligomers which elute in both gradient and isocratic elution within a very small range of eluent compositions $(\Delta \varphi)$ [28].

Enthalpy-entropy-compensation was also tested for both PE and PS oligomers at $40^{\circ} \mathrm{C}$ in $64 \%$ THF. The compensation temperatures which were determined from linear regression analysis of the entire curves for both polymers are $175 \pm 8^{\circ} \mathrm{C}$ for PS and $120 \pm 12^{\circ} \mathrm{C}$ for PE. The significantly lower temperature for $\mathrm{PE}$ is in accordance with the more polar character of this polymer. Critical conditions in reversed-phase systems for such products will be situated at an eluent composition containing less organic modifier or, as an equivalent at a fixed $\%$-modifier, at a lower temperature.

Finally, values of the Gibbs free energy, which were calculated from the obtained enthalpy and entropy values for PS were plotted versus \% THF, which is shown in Fig. 11. It is easily recognized that, especially for the low oligomers, no linear dependence between $\Delta G$ and $\varphi$ is found. This is in accordance with the findings of other workers, who showed that, when a broader range of eluent compositions is taken into account, the dependence between $\varphi$ and $\log (k)$ (and therefore also $\Delta G$ ) can at best be described, using quadratic relationships $[44,45]$. Therefore, at first linear regression in which only data points where (\% THF $>50 \%)$ were taken into account, was performed for all oligomers. It was found that all lines roughly have the same point of intersection at $\Delta G=0$ and $\% \mathrm{THF}$ at which this occurs lies between $83 \%$ and $86 \%$ THF for all oligomers. This is in accordance with results from an earlier study, in which it was found that the so called Critical Solvent Composition (CSC) in a THF-water system on the same column type is $86 \%$ THF [7]. Secondly, when this CSC was taken as a fixed data point and \% THF was fitted versus $\varphi^{2}$, taking into account all data points, including the ones where $\% \mathrm{THF}<50 \%$, regression coefficients for all oligomers exceeded 0.999 .

Obviously from the measurements of thermodynamic parameters under sorption conditions, critical conditions for a polymer can be predicted within certain limits. Furthermore, strong evidence has been obtained for the theoretical prediction that under these conditions the total free energy change equals zero for non-functionalized polymers.

For PE, due to the limited number of different eluent compositions only trends at which the respective oligomers could be determined isocratically, can be given. Nevertheless, when linear extrapolation is 


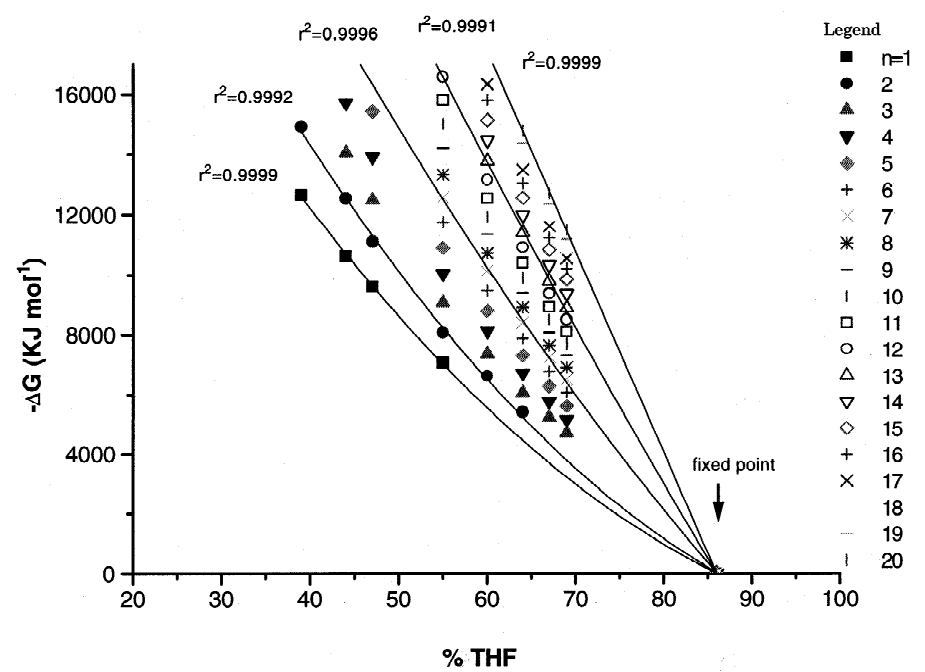

Fig. 11. $\Delta G$ versus $\%$ THF for PS oligomers at $35^{\circ} \mathrm{C}$. Degree of polymerization: see legend. $r^{2}=$ coefficient of regression. Chromatographic conditions: see Section 3.

performed for various oligomers, points of intersection with the $x$-axis lying between $74 \%$ and $80 \%$ THF are found. This indicates that CSC for PE, as could be expected, lies at a lower \%THF. As compared to PS, points of intersection for the respective oligomers show more variation. This is caused by the lower accuracy of determination of retention times. Furthermore, it must be remembered that PE can have three different end group combinations, e.g. 0,1 or 2 alcoholic end groups. The total free energy change of these different solutes under critical conditions will be different (Eq. (5)), thus giving rise to different retention times and different points at which $\Delta G_{\text {total }}$ equals zero.

\section{Conclusions}

Linear van't Hoff plots were obtained for almost all oligomers of both PS and PE. In all cases, negative $\Delta H$ and $\Delta S$ values were found, which both increase for PS as well as for PE with increasing $\%$ THF. The increase in $\Delta H$ can be ascribed to decreasing affinity of the oligomers toward the stationary phase. The increase in $\Delta S$ can be understood from the decreasing number of oligomer sites that will simultaneously interact with the sorbent. The magnitude of $\Delta H$ in all cases exceeded that of
$T \Delta S$, which was even more obvious for PS as compared to $\mathrm{PE}$, indicating that enthalpy plays a more pronounced role in the total retention process than does entropy. For PS, both $\Delta H$ and $\Delta S$ decrease slightly more than linearly with $p$ and it was shown that relations between $\Delta H$ and $\Delta S$, and $p$ can properly be described by the Stockmayer-Fixman equation. Although less clear, similar trends were found for PE.

In the curves of enthalpy and entropy of PS versus $p$ at high \% THF, discontinuities could be observed at an oligomer number slightly less than the carbon number of the bonded chain of the stationary phase. This effect can probably be ascribed to penetration of the oligomer chains into the bonded phase. This is remarkable since the relatively large hydrodynamic volume of PS oligomers due to the bulky aromatic parts, might be expected to hamper penetration. Evidence for these effects could be more clearly obtained from plots of selectivity versus $p$, where two distinct regions with a significantly different slope could be distinguished.

Martin plots for both PS and PE were shown to be non-linear throughout the whole investigated range of eluent compositions, which can be ascribed to the increasing relative importance of entropic effects. This non-linearity found, contradicts the findings of other workers and is suggested to depend on the 
conformation of a polymer in solution, as described by the Stockmayer-Fixman equation. It may therefore be a universal phenomenon for non-polar and moderately polar polymers in the investigated system.

Application of the concept of enthalpy-entropycompensation also revealed a changing retention mechanism with $p$ for PS and PE since no distinct EECT could be found independent of $p$. This probably explains the observation in an earlier study in which no exact molar mass independence of retention could be found under (near) critical conditions. Enthalpy-entropy-compensation was found for all PS oligomers in varying \% THF, indicating that the retention mechanism is independent of the binary eluent composition. This together with the fact that various effects mentioned earlier were shown to occur throughout the whole investigated range of eluent compositions, indicates that conclusions from this study can also be used for a qualitative understanding of the sorption mechanisms in the gradient elution mode.

Finally, it was shown that from plots of $\Delta G$ versus \% THF, critical conditions for PS could be predicted within certain limits. Furthermore, strong evidence was obtained for the theoretical prediction that under these conditions $\Delta G$ equals zero for non-functionalized polymers.

\section{Acknowledgements}

Mr. Huub Borghouts and Ing. Leo van de Ven are kindly thanked for performing the elemental analysis and the NMR measurements, respectively.

\section{References}

[1] G. Glöckner, Gradient HPLC of Copolymers and Chromatographic Cross-Fractionation, Springer Verlag, Berlin, Heidelberg, New York, 1991.

[2] S. Mori, H. Taziri, J. Liq. Chromatogr. 17 (1994) 3055.

[3] K. Rissler, H.P. Kunzi, H.J. Grether, J. Chromatogr. 635 (1993) 89.

[4] P.J.C.H. Cools, F. Maesen, B. Kumperman, A.M. van Herk, A.L. German, J. Chromatogr. A 736 (1996) 125.

[5] D. Berek, Macromol. Symp. 110 (1996) 33.
[6] P. Jandera, J. Urbanek, B. Prokes, H. Blazkova-Brunova, J. Chromatogr. A 736 (1996) 131.

[7] H.J.A. Philipsen, B. Klumperman, A.M. van Herk, A.L. German, J. Chromatogr. A 727 (1996) 13.

[8] H.J.A. Philipsen, B. Klumperman, A.L. German, J. Chromatogr. A 746 (1996) 211.

[9] H.J.A. Philipsen, M. Oestreich, B. Klumperman, A.L. German, J. Chromatogr. A 775 (1997) 157.

[10] H.J.A. Philipsen, M.R. de Cooker, B. Klumperman, A.L. German, J. Chromatogr. A 761 (1997) 147.

[11] H.J.A. Philipsen, B. Klumperman, A.L. German, Proc. Int. GPC. Symp., San Diego, September 1996, submitted.

[12] J.P. Larmann, J.J. DeStefano, A.P. Goldberg, R.W. Stout, L.R. Snyder, M.A. Stadalius, J. Chromatogr. 255 (1983) 163.

[13] M.A. Quarry, M.A. Stadalius, T.H. Mourey, L.R. Snyder, J. Chromatogr. 358 (1986) 1.

[14] H.J.A. Philipsen, unpublished results.

[15] W. Melander, D.E. Campbell, C. Horvath, J. Chromatogr. 158 (1978) 215.

[16] W.R. Melander, A. Nahum, C. Horvath, J. Chromatogr. 185 (1979) 129.

[17] M. Kuchar, E. Kraus, V. Rejholec, V. Miller, J. Chromatogr. 449 (1988) 391.

[18] L.C. Sander, L.R. Field, Anal. Chem. 52 (1980) 2009.

[19] A. Tchapla, S. Heron, H. Colin, G. Guiochon, Anal. Chem. 60 (1988) 1443.

[20] L.A. Cole, J.G. Dorsey, Anal. Chem. 64 (1992) 1317.

[21] L.A. Cole, J.G. Dorsey, K.A. Dill, Anal. Chem. 64 (1992) 1324.

[22] J.G. Dorsey, W.T. Cooper, Anal. Chem. 66 (1994) 857A.

[23] T.C. Pochapsky, Q. Gopen, Protein Sci. 1 (1992) 786.

[24] F.M. Yamamoto, S. Rokushika, H. Hatano, J. Chromatogr. Sci. 27 (1989) 704.

[25] Y. Guillaume, C. Guinchard, J. Liq. Chromatogr. 17 (1994) 2809.

[26] Y. Guillaume, C. Guinchard, J. Liq. Chromatogr. 18 (1995) 3409.

[27] C.H. Lochmüller, M.A. Moebus, Q. Liu, C. Jiang, M. Elomaa, J. Chromatogr. Sci. 34 (1996) 69.

[28] L.R. Snyder, M.A. Stadalius, M.A. Quarry, Anal. Chem. 55 (1983) 14.

[29] S.M. Staverov, A.Yu. Fadeev, J. Chromatogr. 544 (1991) 77.

[30] K.B. Sentell, J.G. Dorsey, J. Liq. Chromatogr. 11 (1988) 1875.

[31] K.A. Dill, J. Phys. Chem. 91 (1987) 1980.

[32] T.C. Schunk, J. Chromatogr. A 656 (1993) 591.

[33] P. Jandera, J. Chromatogr. 449 (1988) 361.

[34] W. Cheng, Anal. Chem. 57 (1985) 2409.

[35] H.M.J. Boots, P.K. de Bokx, J. Phys. Chem. 93 (1989) 8240.

[36] M.A. Stadalius, M.A. Quarry, T.H. Mourey, L.R. Snyder, J. Chromatogr. 358 (1986) 17.

[37] G. Glöckner, Polymer Characterization by Liquid Chromatography, Elsevier, Amsterdam, 1987.

[38] H. Lind, B.Sc. Thesis, Hogeschool Limburg, Sittard, Netherlands (in Dutch).

[39] W.H. Stockmayer, M. Fixman, J. Polym. Sci. C. 1 (1963) 137. 
[40] T.C. Schunk, M.F. Burke, J. Chromatogr. A 656 (1993) 289.

[41] A. Tchapla, H. Colin, G. Guiochon, Anal. Chem. 56 (1984) 621.

[42] S.G. Entelis, V.V. Evreinov, A.V. Gorshkov, Adv. Polym. Sci. 76 (1986) 129.

[43] W.R. Melander, B.K. Chen, C. Horvath, J. Chromatogr. 318 (1985) 1.
[44] P.J. Schoenmakers, H.A.H. Billet, L. de Galan, J. Chromatogr. 185 (1979) 179.

[45] P.J. Schoenmakers, H.A.H. Billet, L. de Galan, J. Chromatogr. 218 (1981) 261. 